\title{
Exudate management and antisepsis in diabetic patients with problem wounds: two case reports
}

This article was published in the following Dove Press journal:

Chronic Wound Care Management and Research

2 June 2017

Number of times this article has been viewed

\section{Luinio S Tongson \\ Dr. James G. Dy Wound Healing and Diabetic Foot Center, Chinese General Hospital and Medical Center, Manila, Philippines}

Introduction: Two cases of large, infected, nonresponding wounds in diabetic patients successfully treated with the combined use of a three-layer, hydrophilic polyurethane foam dressing with SMARTPORE Technology ${ }^{\mathrm{TM}}$ and povidone-iodine formulations are reported. Objective was to provide optimized local wound bed preparation to prepare the wound bed for skin grafting. Presentation of cases: In case 1, a 76-year-old male presented with a 4-day history of bullae formation on the right leg due to necrotizing fasciitis. In case 2, a 65-year-old woman with a chronic right foot ulcer sought medical treatment.

Main observations: In both cases, the combined use of the polyurethane foam dressing and the selective use of various povidone-iodine formulations provided good exudate absorption, lesser pain during dressing changes, infection control and reduced inflammation, thus enabling the successful management of chronic problem wounds in adult diabetic patients.

Conclusion: These cases may further provide clinical data to show that this new polyurethane foam and povidone-iodine products can readily be used together and can be seen as compatible.

Keywords: exudating wounds, polyurethane foam wound dressing, povidone-iodine, TIME framework, wound dressing, management of problem wounds, diabetes mellitus

\section{Introduction}

Wound healing is a critical outcome for all types of tissue injury. ${ }^{1}$ In 2003 , Schultz et al published the TIME framework (tissue management, control of infection and inflammation, moisture balancing, and advancement of epithelial edge of the wound) as a practical guide for managing patients with wounds. ${ }^{2-5}$

Recently, the role of infection and inflammation has been acknowledged ${ }^{3}$ and the positive role of povidone-iodine emphasized, ${ }^{1,4}$ which seems to be especially suited for chronic wounds due to its additional clinically significant anti-inflammatory benefits. ${ }^{5,6}$

Polyurethane foams have gained popularity for their moisture retention properties and good general tolerability, especially for exudating and sloughy wounds. ${ }^{2}$ BETAplast $^{\circledR} \mathrm{N}$ dressing (Mundipharma Distribution $\mathrm{GmbH}$, Manila, Philippines) (a novel three-layer, hydrophilic polyurethane foam) has improved exudate absorption and retention properties, and small pore size (SMARTPORE Technology ${ }^{\mathrm{TM}}$ ), minimizing tissue ingrowth into the dressing, and thus, reduced shearing and less pain during dressing change. ${ }^{7}$

The combined use of this new polyurethane foam dressing and BETADINE ${ }^{\circledR}$ (Mundipharma Distribution GmbH, Manila, Philippines) (povidone-iodine products in many relevant and convenient formats for wound healing) exemplifies chronic wound management that applies the TIME principles. However, little is published on the combined use
Correspondence: Luinio S Tongson Dr. James G. Dy Wound Healing and Diabetic Foot Center, I0th Floor, Medical Arts Building, Chinese General Hospital and Medical Center, Blumentritt, Sta. Cruz, Manila 1014, Philippines Tel $+6327 \mid$ I $414 \mid$

Email Istongsonmd@gmail.com 
of these products. ${ }^{8}$ The purpose of this report is to add to the pool of compatibility data for wound healing devices and antiseptics by describing for the first time the clinical presentation, management and outcomes of two cases of nonhealing wounds in patients with diabetes mellitus (DM) using a combination of a hydrophilic polyurethane foam with SMARTPORE Technology and povidone-iodine. Since these were large wounds, the objective was not wound closure, but local wound management to prepare the wounds for skin grafting. In order for the wound to resume the physiological phases of wound healing, control of infection and inflammation and achieving a clean, granulating wound bed are of critical importance. It should be further noted that the concept of wound bed preparation was derived from surgery to prepare a wound for grafting. ${ }^{3}$

\section{Presentation of cases}

\section{Case I: necrotizing fasciitis}

A 76-year-old male presented with a 4-day history of skin discoloration and bullae formation on the right leg. This patient had a history of uncontrolled DM (HbA1c, 10\%; fasting blood glucose level, $170 \mathrm{mg} / \mathrm{dL}$ ). He had hypertension and atherosclerosis and reported a 10 pack/day smoking history. Pulses were diminished on both lower extremities, from the popliteal pulses to the dorsalis pedis pulses. Monofilament test suggested reduced sensation on both lower extremities, and ankle reflexes were also diminished. Albumin levels were reduced at $28 \mathrm{~g} / \mathrm{L}$. The bulla on the middle third of the right lower extremity measured at $15 \times 10 \mathrm{~cm}$. A second bulla at the dorsum of the right foot measured $10 \times 8 \mathrm{~cm}$, and a third bulla at the medial malleolus measured $5 \times 5 \mathrm{~cm}$. A fourth bulla noted on the medial aspect of the leg measured $20 \times 10$ $\mathrm{cm}$. Ecchymosis and hematomata surrounded these bullae, which exhibited serous to purulent discharge and tenderness. Necrosis of the skin, subcutaneous tissue, and fascia was apparent, with the fascial necrosis extending vertically (Figure 1A). These features, on top of the other clinical symptoms of an infection, led to the diagnosis of necrotizing fasciitis. A swab was taken, and a range of bacteria was isolated including Escherichia coli, Staphylococcus, Klebsiella, and Pseudomonas spp.

Treatment was immediately initiated with empiric piperacillin-tazobactam, along with tetanus prophylaxis and an antithrombotic agent. Surgical debridement was performed, and the patient was referred to the vascular service. The patient eventually underwent sequential sharp debridement with fasciectomy. Multidisciplinary consultation with staff endocrinologists and cardiologists was undertaken to address the patient's metabolic status.
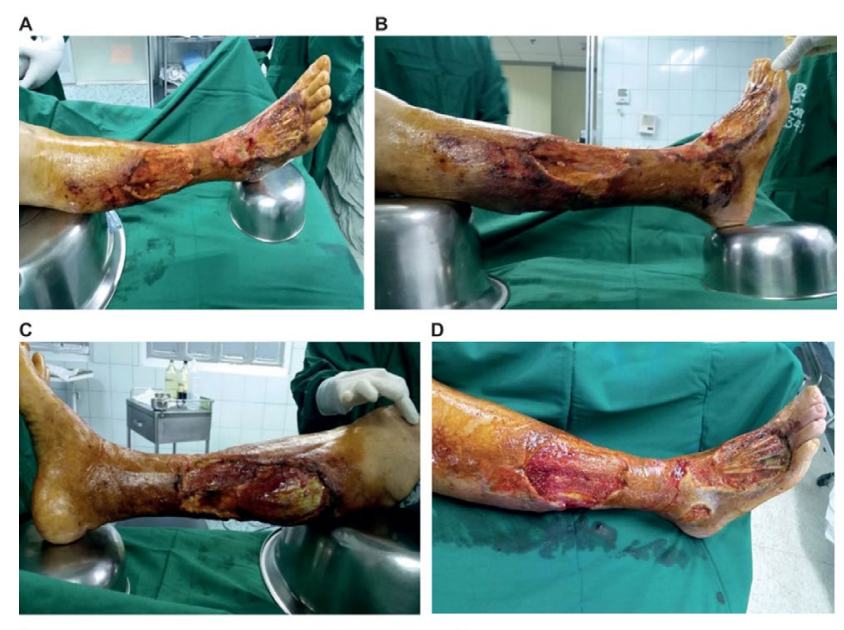

E

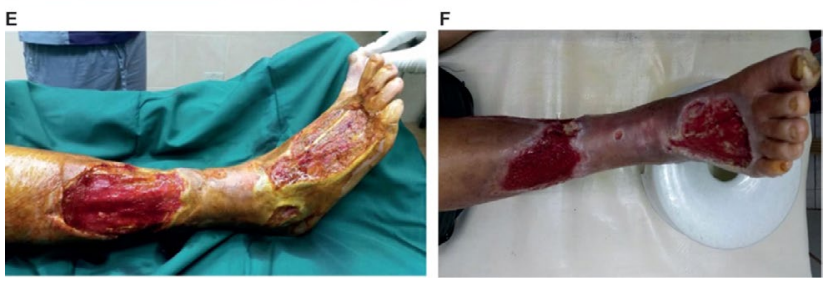

Figure I Time course of wound management with BETAplast ${ }^{\mathrm{TM}} \mathrm{N}$ and BETADINE ${ }^{\circledR}$ in an adult diabetic patient with necrotizing fasciitis.

Note: (A) pre-operative; (B) day 7 (post-operative); (C) day 14; (D) day 30; (E) day 45; (F) day 60 .

A $7.5 \%$ povidone-iodine solution was used for wound and peri-wound area skin cleansing, whereas $10 \%$ povidoneiodine solution was utilized for antisepsis. Polyurethane foam dressing was selected for exudate management. Seven days after the operation, there was still significant necrosis along the edges of the wounds, with infection, tissue sloughing, and moderate discharge (Figure 1B). Tendon exposure was noted. Polyurethane foam dressing was used intermittently over the next 60 days to reduce dressing adherence, along with sterile gauze and negative pressure. A $7.5 \%$ povidone-iodine solution was maintained as cleanser and povidone-iodine dry powder spray was used as a leave-on antiseptic, considering the presence of discharge.

There was significant progress from the 14th to 45 th postoperative day (Figure 1C-1E). Granulation and epithelialization of the wound gradually occurred. Initially, necrosis persisted but eventually abated (Figure 1D). On the 60th postoperative day, infection was completely resolved. Tendon coverage was completed, with minimal discharge (Figure 1F). Granulation was nearly complete. Dressing frequency was typically performed once every 3-4 days, depending on the amount of exudate and the presence of infection. Despite the low albumin, observation of the TIME framework for local wound care proved crucial in the success of this case. At the end of treatment, the wound had no signs of infection, the wound bed exhibited good granulation and epithelization was 
observed along the edges of the wound. The patient was then referred for skin grafting.

\section{Case 2: diabetic foot ulcer}

A 65-year-old housewife complained of a chronic right foot ulcer dating 4 weeks prior to consultation. There was a history of trauma to the right foot. The patient had uncontrolled DM (HbA1c, 11\%; fasting blood glucose level, $180 \mathrm{mg} / \mathrm{dL}$ ). The patient had hypertension and atherosclerosis.

The patient had good pulses at the popliteal artery. Pulses were bilaterally diminished at the level of the dorsalis pedis and posterior tibialis. Monofilament testing demonstrated neuropathy on both feet. Ankle reflexes were reduced on both sides. Albumin was low $(25 \mathrm{~g} / \mathrm{L})$. Upon examination, there was a $15 \times 10 \mathrm{~cm}$ wound with necrotic tissue covering the dorsum of the right foot. The wound was $1 \mathrm{~cm}$ in depth and the surrounding area surrounding showed maceration, with moderate exudate and purulent, foul-smelling discharge (Figure 2A).

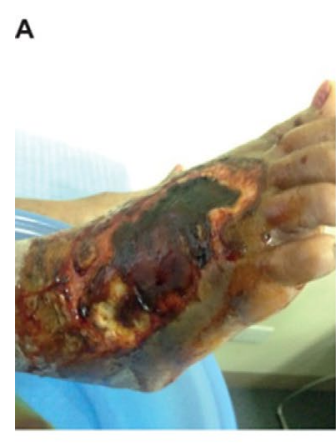

C

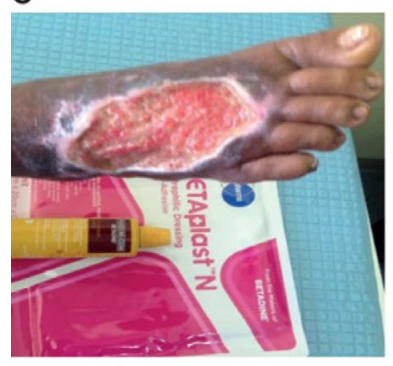

E

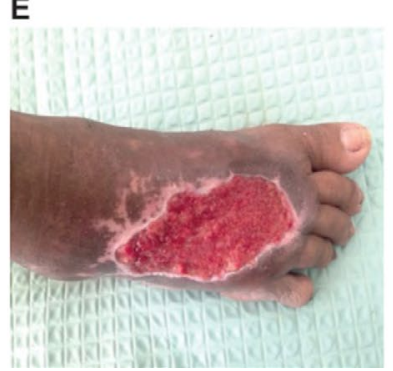

Figure 2 Time course of wound management with BETAplast ${ }^{\mathrm{TM}} \mathrm{N}$ and Betadine ${ }^{\circledR}$ in an adult patient with diabetic foot ulcer.

Note: (A) day 0; (B) day 7; (C) day 14; (D) day 30; (E) day 45.
Debridement was performed with appropriate hemostasis (outpatient setting). After thorough irrigation with normal saline solution, $7.5 \%$ povidone-iodine was used as skin cleanser and $10 \%$ povidone-iodine solution was used as antiseptic. Polyurethane foam dressing was selected to manage moisture. Seven days after debridement, the wound showed moderate exudation. Granulation has initiated and there was no active bleeding. Epithelialization was noted on the edges of the wound (Figure 2B). Treatment was continued. Fourteen days after debridement, the wound still showed moderate discharge and sloughing of granulating tissue (Figure 2C). Sharp debridement was performed using $10 \%$ povidone-iodine solution for initial antisepsis, rinsed off with plain normal saline solution. As there was moderate discharge, povidone-iodine dry powder spray was used as leave-on antiseptic and polyurethane foam dressing was continued. On day 30 , the wound size had decreased to $13 \times 8$ $\mathrm{cm}$ and there was minimal discharge. Infection appeared to have resolved, with increased granulation (Figure 2D). Sixty days after the initial consultation and debridement, the wound size had decreased to $11.5 \times 7 \mathrm{~cm}$ (Figure 2E). There was no recurrence of infection. The patient and the wound care team were highly satisfied with the use of povidone-iodine solutions and spray, and polyurethane foam dressing. The patient reported no pain during dressing changes when the polyurethane foam was employed, and no shearing of new tissue was observed. The patient was eventually recommended to undergo skin grafting due to the size of remaining defect and the overall good status of the wound (Figure 2E).

\section{Main observations}

Patients with DM are especially prone to the development of chronic wounds, such as diabetic foot ulcers and necrotizing fasciitis. About one in seven diabetic patients suffers from diabetic foot ulcer during their lifetime. ${ }^{9} \mathrm{DM}$ is also the most frequent comorbidity in patients with necrotizing fasciitis, a relatively uncommon, but often life-threatening soft tissue infection. ${ }^{10}$ Due to severely impaired wound healing capacity, diabetic patients with foot ulcers or necrotizing fasciitis require optimized wound dressings and antiseptic treatments.

In both diabetic patients with difficult to treat wounds (Figures 1 and 2), the objective was to prepare the wound bed for skin grafting, since the ulcers were of considerable size (Figures 1A and 2A). This required sharp debridement, moisture management, and control of infection and inflammation.

Polyurethane foam dressing was used due to its unique characteristics over other dressings for the management of partial and full-thickness wounds with exudates. ${ }^{7}$ Its SMART- 
PORE Technology polyurethane foam is composed of three layers. The wound contact (inner) layer consists of micropores designed to prevent epithelial cells and fibroblasts from growing into the dressing material, thus reducing shearing and pain during dressing change. The absorptive (middle) layer possesses a high absorption and retention capacity, maintaining an optimally moist environment and preventing exudate leakage. The protection (outermost) layer functions to prevent external contamination and bacterial invasion of the wound tissue. ${ }^{11}$ Both patients in the cases presented here experienced less pain and required less analgesic use during dressing changes with polyurethane foam compared with the other foam dressings used previously. At the same time, polyurethane foam dressing allowed for good exudate absorption, thus promoting progressive healing of these problematic wounds (Figures 1B and F and 2B and E). Unlike occlusive dressings, polyurethane foam dressings are permeable to both gases and water vapor, an important feature to prevent, for example the growth of anaerobic bacteria.

Iodine has been used in wound care and antisepsis since antiquity. ${ }^{1,12}$ Its antimicrobial spectrum includes Grampositive and Gram-negative bacteria, protozoa as well as fungi and viruses. ${ }^{13}$ Although some in vitro studies suggest that povidone-iodine is toxic to human fibroblasts, ${ }^{14}$ this is not a consistent finding, ${ }^{15,16}$ and in vitro activity of povidoneiodine may be affected by reaction with the culture medium. ${ }^{15}$ Systematic reviews of clinical data concluded that iodine is an effective antiseptic agent that deserves to retain its place among the modern antiseptic agents. ${ }^{1,4}$ In comparison to other antiseptic agents (e.g., silver sulfadiazine cream), iodine-containing treatments were superior in reducing bacterial count and/or wound size. At the same time, no evidence was found to support the notion that iodine might delay wound healing. ${ }^{1}$ Furthermore, unlike with antibiotics, there has been no report of bacterial resistance, possibly due to povidone-iodine's mode of action. In brief, free iodine (from povidone-iodine) readily diffuses through microbial membranes. Once inside the cell, iodine readily oxidizes biomolecules (especially proteins), subsequently leading to loss of function and, ultimately, inactivation of pathogens. ${ }^{17}$ Similarly, the safety and efficacy of povidone-iodine in (chronic) wound healing have been positively evaluated. ${ }^{4}$ Although povidone-iodine-containing antiseptic formulations are usually well-tolerated, precautions (e.g., in case of radioiodine scintigraphy or when used in newborns and small infants) and contraindications (e.g., hypersensitivity to iodine, hyperthyroidism, and acute thyroid disease) require special attention for the judicious use of iodine in the management of chronic wounds. ${ }^{13}$ The two diabetic patients treated with povidone-iodine products experienced good infection control, a cleaner wound bed and overall reduced inflammation. In addition, the patient with necrotizing fasciitis reported a pleasant cooling effect of the povidoneiodine dry powder spray. The combined use of polyurethane foam dressing and povidone-iodine dry powder spray, which has not been reported yet, also received favorable feedback from the attending wound care team, especially regarding the hygienic advantages of the dry powder which avoids direct wound contact.

\section{Conclusion}

Here, we presented two cases of chronic problem wounds managed with a previously under-studied combination of polyurethane foam dressing and povidone-iodine solutions and/or spray. The encouraging results obtained in these two clinical cases demonstrate not only the compatibility of polyurethane foam dressings and povidone-iodine antiseptic formulations, but also that their combined use as part of the TIME framework allows for the successful management of chronic problem wounds in adult diabetic patients and possibly beyond.

\section{Acknowledgments}

BETADINE and BETAplast are registered trademarks of Mundipharma AG, SMARTPORE Technology is a trademark of Mundipharma AG. The author would like to acknowledge Mundipharma Pte Ltd for commissioning MIMS Pte Ltd to provide writing assistance and editorial support. The views expressed in this manuscript are solely those of the author. This research did not receive any specific grant from funding agencies in the public, commercial, or not-for-profit sectors. Both patients provided written informed consent for publication of the case reports and the accompanying images.

\section{Disclosure}

DrTongson reports personal fees from Mundipharma, outside the submitted work. The author reports no other conflicts of interest in this work.

\section{References}

1. Vermeulen H, Westerbos SJ, Ubbink DT. Benefit and harm of iodine in wound care: a systematic review. J Hosp Infect. 2010;76(3):191-199.

2. Schultz GS, Sibbald RG, Falanga V, et al. Wound bed preparation: a systematic approach to wound management. Wound Repair Regen. 2003; 11 (Supp1 1):S1-S28.

3. Leaper DJ, Schultz G, Carville K, Fletcher J, Swanson T, Drake R. Extending the TIME concept: what have we learned in the past 10 years? Int Wound J. 2012;9 (Suppl 2):1-19. 
4. Leaper DJ, Durani P. Topical antimicrobial therapy of chronic wounds healing by secondary intention using iodine products. Int Wound J. 2008;5(2):361-368.

5. Al-Kaisy AA, Salih Sahib A. Role of the antioxidant effect of vitamin e with vitamin $\mathrm{C}$ and topical povidone-iodine ointment in the treatment of burns. Ann Burns Fire Disasters. 2005;18(1):19-30.

6. Beukelman CJ, van den Berg AJ, Hoekstra MJ, et al. Anti-inflammatory properties of a liposomal hydrogel with povidone-iodine (Repithel) for wound healing in vitro. Burns. 2008;34(6):845-855.

7. Lee SM, Park IK, Kim YS, et al. Physical, morphological, and wound healing properties of a polyurethane foam-film dressing. Biomater Res. 2016;20:15.

8. Eberlein T, Hoffmann M, Asmussen PD, et al. Results of testings for compatibility of a hydrosomal wound gel with different modern wound dressings. Zeitschrift fuer Wundheilung. 2006;2:62-67.

9. Yazdanpanah L, Nasiri M, Adarvishi S. Literature review on the management of diabetic foot ulcer. World J Diabetes. 2015;6(1):37-53.

10. Misiakos EP, Bagias G, Patapis P, et al. Current concepts in the management of necrotizing fasciitis. Front Surg. 2014;1:36.
11. Park YO, Minn KW, Hur JP. The effect of Medifoam (hydrophilic polyurethane foam) dressing in split thickness skin graft donor site. Korean Soc Plastic Reconstr Surg. 2002;29:297-301.

12. Angel DE, Morey P, Storer JG, et al. The great debate over iodine in wound care continues: a review of the literature. Wound Pract Res. 2008;16(1):6-21.

13. Zamora JL. Chemical and microbiological characteristics and toxicity to povidone-iodine solutions. Am J Surg. 1986;151(3):400-406.

14. Balin AK, Pratt L. Dilute povidone-iodine solutions inhibit human skin fibroblast growth. Dermatol Surg. 2002;28(3):210-214.

15. Müller G, Kramer A. Biocompatibility index of antiseptic agents by parallel assessment of antimicrobial activity and cellular cytotoxicity. J Antimicrob Chemother. 2008;61(6):1281-1287.

16. Rabenberg VS, Ingersoll CD, Sandrey MA, Johnson MT. The bactericidal and cytotoxic effects of antimicrobial wound cleansers. J Althl Train. 2002;37(1):51-54.

17. Lachapelle J, Castel O, Casado F, et al. Antiseptics in the era of bacterial resistance: a focus on povidone iodine. Future Med. 2013;10 $579-592$.
Chronic Wound Care Management and Research

\section{Publish your work in this journal}

Chronic Wound Care Management and Research is an international, peer reviewed, open access, online journal publishing original research, reviews, editorials, and commentaries on the causes and management of chronic wounds and the major issues related to chronic wound management. Topics also include chronic wounds as comorbidities to other

\section{Dovepress}

conditions, patient adherence to therapy, and the economic burden of chronic wounds. The manuscript management system is completely online and includes a very quick and fair peer review system, which is all easy to use. Visit http://www.dovepress.com/testimonials.php to read real quotes from published authors. 